\section{Multiple giant cavernous angiomas of the brain}

Sir,

Cavernous angioma (CA) of central nervous system (CNS) is an uncommon disease and presents with seizures, hemorrhagic episodes, and rarely with focal deficits. ${ }^{[1]}$ Multiple CAs are often familial. Giant CAs (GCAs) are extremely rare and multiple GCAs are sill rarer. Sometimes, these lesions can be fatal from massive hemorrhage. Most GCAs present as multicystic lesions with hemosiderin ring around on MRI giving a 'bubbles of blood' appearance ${ }^{[2]}$ Radiofrequency thermocoagulationassisted surgery ${ }^{[3]}$ and neuronavigation ${ }^{[4]}$ have been advocated by some to treat such lesions with minimal blood loss and precision, respectively. We report a case with multiple CAs with two of the lesions assuming a giant size (more than $4 \mathrm{~cm}$ in diameter).

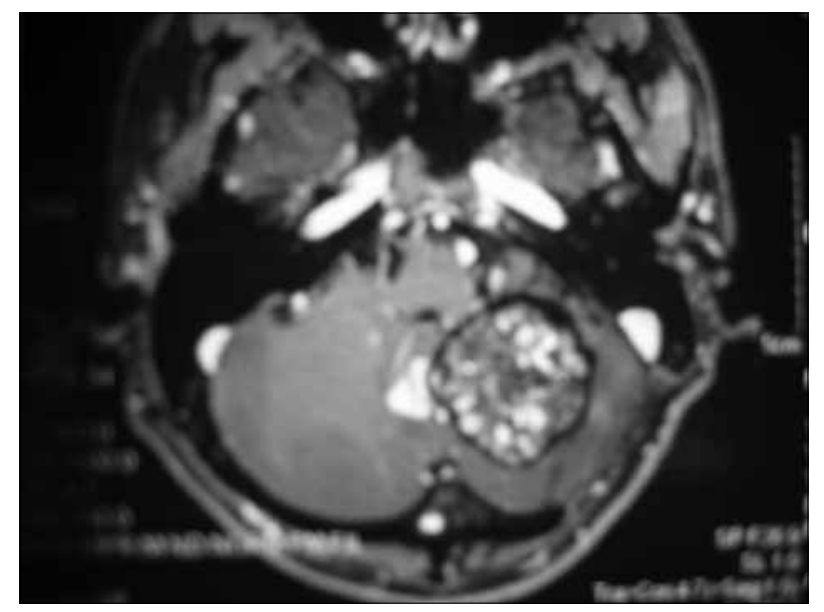

Figure 1: Axial T-2 weighted image showing a left cerebellar lesion

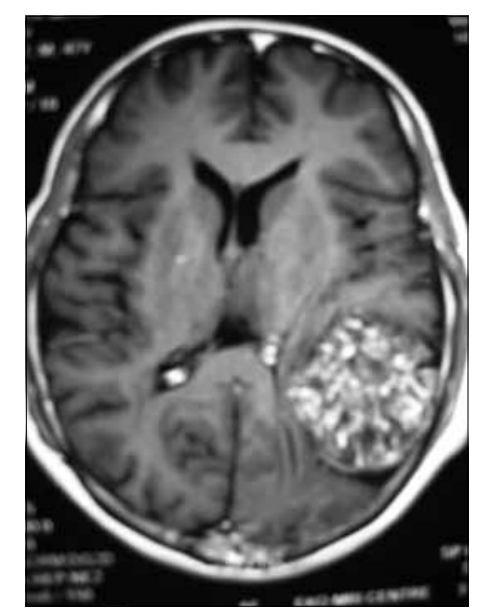

Figure 2: Axial T-1 weighted image showing a left parietal lobe cavernous angioma with 'bubble of blood' appearance

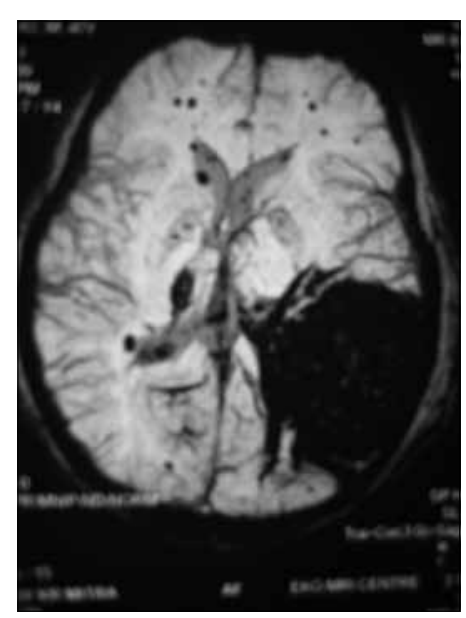

Figure 3: Gradient sequence image showing multiple lesions in both the cerebral hemispheres with evidence of hemorrhage inside

A 46-year-old male, was operated for a left cerebellar CA in 1984, a ventriculoperitoneal shunt followed by total excision of the lesion was done. Postoperatively he had improved completely. Follow-up brain computerized tomography (CT) in 1991 showed a left parietal CA. As he was asymptomatic, surgery was not advised. Subsequently, the patient was lost to follow up. In the present admission he was admitted for severe headache, vomiting and ataxia. Magenetic resonance imaging (MRI) of brain revealed a giant cavernoma measuring $5.3 \mathrm{~cm}$ in diameter in the left parietal lobe [Figure 1] and another slightly smaller recurrent lesion in the left cerebellar hemisphere measuring $4.2 \mathrm{~cm}$ in diameter [Figure 2]. There were in addition multiple small lesions in both the cerebral hemispheres with evidence of minor hemorrhages [Figure 3]. There was no history of similar illness in the family. Through a combined approach (posterior fossa and supratentorial parieto-occipital craniotomy), both these lesions were excised completely by standard microsurgical techniques. The patient had an uneventful postoperative recovery. A follow-up CT scan revealed complete excision of the two giant CAs. The diagnosis of CA was confirmed by histopathological examination. At the time of discharge, he had minimal ataxia.

\section{N. Tripathy, S. N. Singh}

Apollo Gleneagles Hospitals, Kolkata, India. 58, Canal Circular Road, Kolkata - 700054 E-mail: laxmitripathy@yahoo.co.uk DOI: 10.4103/0028-3886.53267

\section{References}

1. Gelal F, Feran H, Rezanko T, Vidinli BD. Giant cavernous angioma of the temporal lobe: A case report and review of the literature. Acta Radiol 2005;46:310-3.

2. Kan P, Tubay M, Osborn A, Blaser S, Couldwell WT. Radiographic features of tumefactive giant cavernous angiomas. Acta Neurochir 
(Wien) 2008;150:49-55.

3. Hu W, Li L, Shi D, Guo F, Wei D, Gu P, Miao Y, Chen G. Radiofrequency thermocoagulation-assisted surgery for intracranial giant vasogenic tumors. Surg Neurol 2008;70: 570-4.

4. Rohde V, Spangenberg P, Mayfrank L, Reinges M, Gilsbach JM, Coenen VA.

Advanced neuronavigation in skull base tumors and vascular lesions. Minim Invasive Neurosurg 2005;48:13-8.

Accepted on 07-03-2009 